\title{
Ingestion of foreign
}

bodies in children: the experience of a third-

\section{level single center from 2001 to 2012}

BY CARMELA GL RAFFAELE, DONATO RIGANTE, SILVIA PULITANÒ, ALdO MANCINO, MARCELLO COVINO, ALESSANDRO BARELLI, PAOLO MAURIZIO SOAVE, LUCA TORTOROLO

Foreign body (FB) ingestion in pediatrics is a worldwide problem of significant relevance especially for children aged 6 months-3 years. $(1,2)$ We have performed a retrospective collaborative study to evaluate features and outcomes of FB ingestions in all o-to-18-year-old patients from January 2001 to December 2012 in our polyclinic. Our evaluation was performed using the GIPSE database, recording and tabulating patient's age and sex, hours and month of admission to the emergency department, type of FB ingested, symptoms, examinations performed, advice required, type of therapy, and data about eventual hospitalization, in a specific database.

A total of 56 patients ( 28 boys and 28 girls) with suspected FB ingestion were recruited. The highest incidence occurred in the first 3 years of life (32 children, 57\%), with a peak in patients aged 1-2 years, while between 3 and 18 years we found 24 patients (43\%). Table 1 lists all FBs ingested. Different reasons explain the vulnerability of the 6 month-3 year age group, as the natural tendency of the young child to put different objects in his/her mouth and even swallow them: they live the "oral phase" of their psycho-emotional development and the child begins to relate 
him/herself with the outer world through the mouth. However, in these children FB ingestion is an accidental event, unlike older children and adolescents or young adults with mental retardation, who intentionally ingest FBs. (3) The highest incidence (42.9\%) of FB ingestion occurred at home in the night-time from 8 p.m. to 8 a.m., confirming the hypothesis that children engaged in school activities in the morning are under closer supervision of teachers, while during the evening they are more "free" to explore the environment, taking advantage of distractions by parents and caregivers. A higher incidence was noted in January (11 cases, 19.6\%) and May (7 cases, $12.5 \%$ ); a lower incidence in March (only 1 case, $1.8 \%$ ). Grouping the months into seasons, the same effect was present in autumn and winter with an equal incidence of $29 \%$, while $23 \%$ was the incidence in summer and $19 \%$ in spring. With regard to the type of FB ingested, as already reported in the medical literature, (4) objects most commonly ingested were metals (32\%) and food (14\%). Only a very small percentage of patients (7\%) ingested pieces of glass or batteries. Even synthetic objects (13\%), plastics (12\%), objects of natural origin (2\%), and magnets (2\%) were accidentally ingested. In $11 \%$ of cases the ingested object was unidentified and remained unknown even after radiological examination. In regard to symptoms manifested by patients, $62.5 \%$ arrived in the Emergency Department without showing any symptoms at all. While the remaining $37.5 \%$ had common symptoms, such as nausea, vomiting, cyanosis, retrosternal pain, difficulty breathing, odynophagia, abdominal pain, impaired speech, or crying, in full compliance with the medical literature. (5) In our series, no examination or laboratory text was performed, except for one patient, a 2-year-old girl who presented with repeated episodes of vomiting after ingesting a $2 €$ coin. Radiological examinations were required in 49 cases, proving that X-ray films can help locate FBs. Expert consultations were carried out in $54 \%$ of cases: a surgical visit was required in 18 patients (32\%), an ENT visit in 6 (11\%), and a radiologic consultation in 2 (4\%). The Poison's Center was contacted in cases of ingestion of fragments of thermos, putty rubber, polyester, and only in the latter case was it recommended to administer magnesium hydroxide and aluminum. The resuscitator was called in the case of ingestion of a battery. Finally, with regard to hospitalizations, only $15 \%$ of children were hospitalized. In our series, cases were 
uncomplicated, as all objects ingested were spontaneously eliminated, but the ingestion of FB can be dangerous. When FBs are small and blunt the overall prognosis can be usually good; for large-sized or sharp FBs (such as needles) it should be appropriate to contact the nearest Emergency Room for a clinical and/or instrumental thorough examination of the specific case.

Table 1. List of foreign bodies ingested by children evaluated in the Polyclinic A. Gemelli during the period 2001-2012.

\begin{tabular}{|c|c|c|}
\hline \multirow[t]{2}{*}{ Food } & \multirow{2}{*}{$\begin{array}{l}\text { olive pits } \\
\text { chips }\end{array}$} & \multirow{2}{*}{$\begin{array}{c}2 \\
- \\
1\end{array}$} \\
\hline & & \\
\hline & fish bones & 2 \\
\hline & candies & 2 \\
\hline & egg shell & 1 \\
\hline \multirow[t]{3}{*}{ Glass } & marble & 1 \\
\hline & fragments of jar & 2 \\
\hline & fragment of thermos & 1 \\
\hline \multirow[t]{5}{*}{ Metal products } & coins & 9 \\
\hline & braces & 1 \\
\hline & steel balls & 6 \\
\hline & rings & 1 \\
\hline & earrings & 1 \\
\hline \multirow[t]{6}{*}{ Plastic items } & polyester & 1 \\
\hline & plastic disc & 1 \\
\hline & pacifier & 1 \\
\hline & button & 1 \\
\hline & whistle & 1 \\
\hline & $\begin{array}{l}\text { plastic toy phone } \\
\text { antenna }\end{array}$ & 1 \\
\hline
\end{tabular}


Magnets

part of magnetic board $\quad 1$

Batteries

Objects of natural origin pebble 1

Objects of synthetic nature

kneaded eraser $\quad 2$

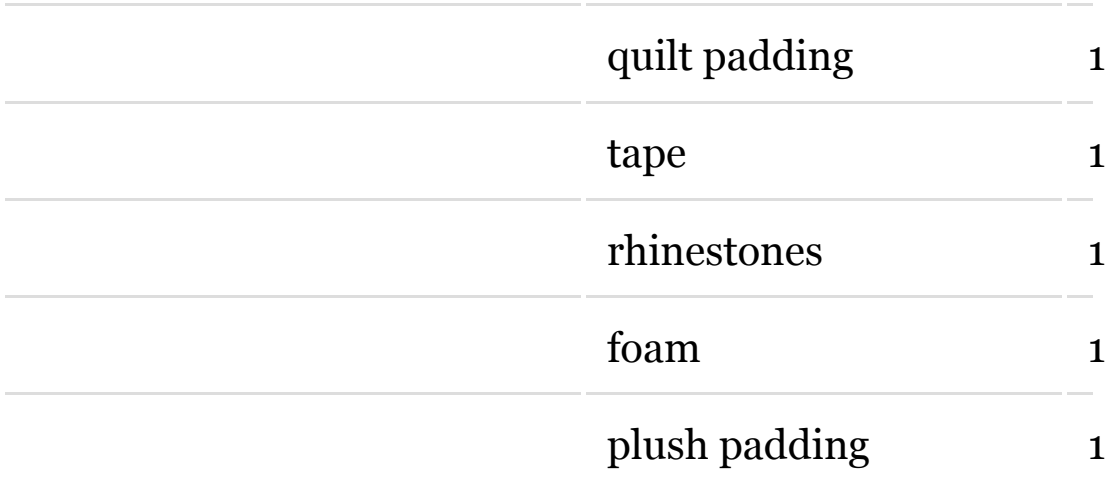

Unidentified objects

6

\section{References}

1. Jackson CL. Foreign bodies in air and food passages. Postgrad Med 1948;4:281-90.

2. Pak MW, Lee WC, Fung HK, Hasselt CA. A prospective study of foreign body ingestion in 311 children. Int $\mathrm{J}$ Pediatr OtorhinoLaryngol 2001;58:37-45.

3. Gasparella M, Ferro M, Marzaro M, Perrino G. Ingestione di corpi estranei in età pediatrica. Reparto Clinicizzato di Chirurgia Pediatrica, Treviso 2009.

4. Arms JL, Mackenberg-Mohn MD, Bowen MV, Chamberlain MC, Skrypek TM, Madhok M, et al. Safety and efficacy of a protocol using bougienage or endoscopy for the management of coins acutely lodged in the esophagus: a large case series. Ann Emerg Med 2008;51:367-72.

5. Michaud L, Bellaïche M, Olives JP. Groupe francophone d'hépatologie, gastroentérologie et nutrition pédiatriques (GFHGNP). Ingestion of foreign bodies in children. Recommendations of the French-Speaking Group of Pediatric Hepatology. Gastroenterol Nutr Arch Pediatr 2009;16:54-61. 
Article printed from Signa Vitae: http://www.signavitae.com

URL to article: http://www.signavitae.com/2015/12/ingestion-offoreign-bodies-in-children-the-experience-of-a-third-levelsingle-center-from-2001-to-2012/

Copyright (C) 2015 Signa Vitae. All rights reserved. 